\title{
Os leitores brasileiros na era pulp: 0 advento das revistas de emoção
}

\author{
RESUMO
}

Rhuan Felipe Scomação da Silva rfss hcp@hotmail.com

Universidade Estadual de Ponta Grossa (UEPG), Ponta Grossa, Paraná, Brasil.

\section{Evanir Pavloski}

Universidade Estadual de Ponta Grossa (UEPG), Ponta Grossa, Paraná, Brasil.
O presente artigo procura articular a relação de leitura no cenário literário brasileiro do início do século XX com as famosas revistas Pulp, aqui conhecidas como revistas de emoção. Trabalhando com um nicho de mercado durante as últimas décadas, revistas como Weird Tales, Tales From the Crypt e Mysterie Magazine formaram uma considerável legião de leitores enquanto estavam em publicação. Tais revistas foram um importante caminho para que muitos leitores criassem seus horizontes de leitura e ambiente de escrita, construindo o universo literário de diversos brasileiros. Os textos de Marisa Lajolo e de Regina Zilberman sobre a leitura, e de Roberto Causo sobre o Pulp no Brasil formulam a base teórica deste trabalho, enquanto Iser e Gennete trabalham o discurso da narrativa e o reflexo do leitor no contato com essas obras. Esse conjunto de autores promovem uma importante análise desse impacto na cultura de leitura dos brasileiros, o que acabará norteando um considerável grupo de leitores pouco visados em pesquisas acadêmicas.

PALAVRAS-CHAVE: Pulp. Revistas de emoção. Ficção Científica. Fantasia. 


\section{INTRODUÇÃO}

O final do século XIX, assim como o início do século XX, foram períodos em que a leitura de revistas populares alcançou seu patamar mais amplo. $O$ aumento do número de leitores, ocasionado pelo empenho na alfabetização universal, principalmente em países que ampliavam seu poderio comercial com as indústrias, além da alta comercialização de jornais e revistas que buscavam um novo leitor de entretenimento, foram as principais causas do amplo aspecto em que países como Estados Unidos, Inglaterra e França tornaram seu mercado livreiro um novo ambiente para experimentações literárias, como bem aponta Causo (2014) em seu artigo sobre o Pulp no mundo.

Essa tendência, motivada por um novo público sedento por experimentações e novas formas de vivenciar aventuras, caminhava ao encontro de um leitor já acostumado com o romance folhetim, gênero este que preenchia um espaço considerável das bibliotecas e dos espaços livreiros desses países, mas que começava a perder seu poderoso fôlego dos séculos XVIII e XIX, abrindo espaço para novas publicações literárias de gênero, principalmente o policial, a ficção científica e o mistério.

Como aponta Causo (2014 p.1), "A tendência dessas publicações, ainda no século XIX, era descobrir gêneros literários que falassem das ansiedades contemporâneas a um novo público urbanizado, dinâmico, interessado em ciência e tecnologia, e em aventuras e expedições a terras distantes". Um novo público começava a formar o que conhecemos hoje como um nicho de mercado que foi extremamente rentável, mas que naquela época era visto como uma nova e, digase de passagem, aterrorizante aposta pelos editores e escritores.

Ampliar então esse ambiente para revistas de gênero transpareceu como um mecanismo comum e esperado por uma parcela desses editores, pois foi desse ponto que revistas como The Strand Magazine, criada por George Newnes em 1891, dando vida a um dos personagens mais conhecidos do gênero, Sherlock Holmes, pelo escocês Arthur Ignatius Conan Doyle, ou a The Iddler, com narrativas de ficção científica de Mark Twain e H. G. Wells, deixaram suas impressões na história literária desse período.

Dentro desse nicho, mas focando em histórias de horror e fantasia, a Weird Tales, revista que tornou famoso Howard Philips Lovecraft, um dos escritores basilares do horror cósmico, tornou-se uma das maiores referências quanto ao tema fantástico, introduzindo ao leitor uma forma menos aventuresca e mais psicológica a suas narrativas.

A revista torna o Pulp algo além do divertimento descompromissado em que se fixava na maioria de seus lançamentos, apresentando ao leitor um ambiente menos seguro, insípido e pronto para tirá-lo de sua zona de conforto.

Contudo, será com Amazing Stories que a ficção científica terá seu grande pilar. A revista criada por Hugo Gernsback, considerado um dos maiores investidores do gênero, formaria o que hoje conhecemos como fiç̧ão científica clássica.

Os maiores temas do gênero, como as Space Operas, aventuras que exploram viagens por planetas distantes, encontros com criaturas e ambientes desconhecidos, geralmente narrados a partir de uma nave espacial, com um grupo 
de tripulantes heterogêneos, geralmente estereotipados, são conhecidos hoje principalmente pela publicação dessas revistas e por sua importância na divulgação e alcance desse gênero para a massa que angariava novas formas de leitura.

Vale lembrar, apenas a título de curiosidade, que um dos maiores prêmios dados a escritores de ficção científica, horror e fantasia desde então tem como nome Prêmio Hugo, em homenagem ao criador da Amazing Stories.

Como metodologia, o trabalho apontará momentos da história dessas revistas em que o cenário nacional se viu aberto para sua recepção, destacando estágios de sua evolução quanto à recepção dos leitores e alterações que se fizeram necessárias conforme o sistema editorial entendia seu público alvo.

O trabalho parte da perspectiva sobre o reconhecimento do leitor brasileiro desde os primórdios de sua recepção no universo editorial e acadêmico, até a função pessoal e social que recebeu posteriormente. Para Marisa Lajolo e Regina Zilberman $(2003,2015)$, a pergunta "Quem é o leitor?" dará embasamento para pensar sua vinculação e ação no meio que existe.

Para responder a esse questionamento, as autoras caminham por vários períodos de percepção desse leitor no Brasil, desde a expansão da imprensa até a função social do mesmo.

\begin{abstract}
Se não podemos escrever a biografia do leitor, temos condições de narrar sua história, que começou com a expansão da imprensa e desenvolveu-se graças a ampliação do mercado do livro, à difusão da escola, à alfabetização em massa das populações urbanas, à valorização da família e da privacidade doméstica e à emergência da ideia de lazer. Ser leitor, papel que, enquanto pessoa física, exercemos, é função social, para a qual se canalizam ações individuais, esforços coletivos e necessidades econômicas. (LAJOLO; ZILBERMAN, 2003, p.14)
\end{abstract}

Essa percepção, aliada ao amplo levantamento desse leitor com as Pulp Fictions por Causo $(2003,2014)$, forma o arcabouço teórico central deste trabalho, evidenciando o lugar e tempo em que essas revistas atuaram.

Sua percepção sobre o ambiente nacional de leitura abrange não apenas sua colocação no mercado e especificações técnicas, como também pontuações sobre recepção e longevidade dessas revistas.

Embasado nessas propostas, o artigo tentará articular as referências com que tais revistas trabalham seu caminho, quais dificuldades encontraram em seu terreno de atuação e como percebiam as mudanças que se faziam necessárias conforme seu público alterava o que procurava como leitura.

Para tanto, as propostas de Zilberman (2015) e Lajolo (2003) quanto à construção do leitor e da leitura no Brasil se farão referência central nessa análise, pois trabalharão com as nuanças desse público leitor em referência a tudo o que vinha sendo publicado, além da recepção e intencionalidade com que essas revistas eram vistas por seus leitores, escritores e editores. 
Abrindo espaço para uma discussão que ainda possui resistência intensa de uma grande massa de leitores, a ficção científica, o suspense e o terror entram na grande avalanche de publicações com uma proposta singular de recepção.

Os pensamentos das autoras sobre o leitor brasileiro ajudarão a formar uma percepção, mesmo que tênue em um primeiro momento, do que foi o processo de entendimento e aceitação do público dessa literatura que foi considerada, até pouco tempo atrás, como literatura menor.

Seu papel na construção do imaginário do leitor brasileiro se mostrará evidente e, podemos afirmar com certa segurança, imprescindível para que hoje, com o afastamento necessário, possamos criar um horizonte onde é possível analisar e entender o impacto dessas leituras no imaginário nacional.

A partir desses pensamentos, tomamos também como arcabouço teórico alguns textos de Causo (2014) sobre as revistas Pulp nacionais. O autor, detentor de um considerável acervo de trabalho teórico sobre o tema, formará a base referencial da recepção do material no Brasil, além de um breve histórico internacional dessas revistas e de seus caminhos até solo nacional.

Não precisando nos ater a uma pesquisa historiográfica, será possível aproximar sua leitura do ambiente Pulp à que as autoras apresentam da leitura e dos leitores no Brasil. Com esse efeito o trabalho possibilitará uma análise mais sucinta e direta do objeto de pesquisa, efeito esse que tentará ampliar o que foram ou ainda são as revistas de emoção no Brasil.

\section{AS REVISTAS NO BRASIL}

No Brasil, a chegada dessas revistas tardou a acontecer. Isso se motivou principalmente pela dificuldade em trazer tais periódicos do exterior e pela falta de investimentos dos editores nacionais em acreditar no gênero. Apesar do folhetim já ser um amplo espaço de divulgação literária no começo do século XX, será apenas em 1930 que textos ficcionais do gênero alcançam seu espaço em solo nacional.

Esse atraso em relação aos Estados Unidos, França e Inglaterra tem uma conexão evidente com a descrença no público leitor nacional. Preencher esse espaço de publicação se mostrava como um investimento de grande risco e com grande possibilidade de vazio mercadológico.

Isto se demonstrou pelas novas empreitadas em uma criação literária nacional e no afastamento do texto estrangeiro, evidenciando uma literatura original e desconectada de padrões externos, em desencontro dos investimentos em ampliar a percepção de leitura e alcance da massa de leitores, como Causo (2003) explana no decorrer de seu texto.

Apesar desse embate, e da difícil entrada e permanência do gênero no Brasil, o folhetim consegue abrir espaço entre a enxurrada constante, e aparentemente interminável, de publicações originais, plágios e cópias sem referências ao original, para esse novo gênero, e já em 1857 uma publicação desponta como uma das primeiras ficções científicas nacionais, O fim do mundo em 1857, de Joaquim Manoel de Macedo (CAUSO, 2014, p.3). 
Foi apenas em 1934 que a primeira Pulp brasileira entrou em circulação. Sob o nome de Romance Mensal: Uma Revista Diferente das Outras, lançada em julho de 1934 pela Companhia Editora Moderna, a revista arrisca explorando leituras que vinham de acordo com as Pulps estrangeiras, com a tradução de um texto publicado alguns anos antes e outros contos de escritores nacionais que mesclavam o horror, o policial, o suspense e a fantasia.

Causo inclusive traz um excerto da própria revista, a qual se compara a seus originais apenas pelo tema, em um esforço claro em trazer para o leitor brasileiro algo novo e de produção nacional, apesar de, como pontuado pela própria revista, possuir menos qualidade.

\begin{abstract}
A Revista que estás lendo, não tem a pretensão de ser comparada ás suas co-irmãs mais elegantes e famosas. Aliás, pelo seu preço, isso não poderia siquer pretender. É uma revista econômica, feita para o grande público, e que só tem um objectivo: familiarizar o leitor com a obra dos modernos escriptores nacionaes e extrangeiros, não medindo esforços, não poupando sacrificios. [...] Com relação á parte literaria, basta esclarecer que adoptaremos o maior critério na selecção dos trabalhos, afim de que "Romance Mensal" possa ser lido por todos, sem distincção de edade e de sexo. [...] (CAUSO, 2014, p.45)
\end{abstract}

Contudo, com certo sucesso adquirido graças à boa recepção do público, seu editorial altera a forma de apresentação da revista, pontuando-a como algo de importância relevante ao público nacional, fonte de informação, diversão e intelectualidade para os lares, como também citado no texto de Causo:

\footnotetext{
"Romance Mensal", que deverá tornar-se, dentro em breve, a revista preferida das pessoas de fino gosto litterario, e o mensario de leitura obrigatória em todos os lares, pois, embora publique os mais interessantes e variados trabalhos, não deixará de proporcionar apenas leitura sã, agradável e proveitosa. (CAUSO, 2014, p.6)
}

A Novela, revista lançada em 1936, foi a primeira a trazer uma edição especial apenas com narrativas de horror (CAUSO, 2014), publicando clássicos como $O$ Horla, de Guy de Maupassant, O Coração Delator, de Edgar Alan Poe, e A Garra de Macaco, de W. W. Jacobs. A revista conseguiu criar um novo ambiente para leitores que procuravam um gênero mais novecentista de narrativa fantástica, apresentando um novo horizonte a ser explorado, além de descortinar esse espaço para diversas revistas que viriam em seu encalço nos anos seguintes.

Com principal fonte de referência das cultuadas Tales From The Crypt e Weird Tales, esses periódicos dedicavam seus espaços exclusivamente a obras que trabalhassem com o fantástico, um nicho de mercado muito atuante nos Estados Unidos, mas seleto a um pequeno público no Brasil. 
A partir disso, A Novela acabou sendo apresentada como referência para diversas outras revistas que dedicariam seu editorial e publicações exclusivamente para o gênero horror, como a Cripta, a Spektro e a Mestres do Terror, uma das revistas mais duradouras do gênero horror, que abordando o tema a partir dos quadrinhos, acabaram ampliando o espectro de leitores para um novo patamar.

Apesar de o horror folhetinesco ter entrado com afinco nas revistas Pulp nacionais e internacionais no século XX, será com as famosas Penny Dreadfuls que todas essas narrativas conseguirão abrir espaço no ambiente de leitura, principalmente estadunidense, do século XIX.

Angariando um espaço antes seleto aos romances de gêneros que se pautavam pela crítica acadêmica e com referenciais éticos, as Penny Dreadfuls apresentaram ao leitor um novo ambiente de leitura que escapava aos padrões estilizados de sua época, demonstrando uma fuga do usual do romance e um investimento em temas dogmáticos e de alta perplexidade por um público não acostumado a tais características.

As Penny Dreadfuls foram revistas com narrativas curtas, vendidas em espaços diversos a preços baixíssimos, geralmente com ilustrações que representavam à história narrada. Além de possuírem grande apelo social, costumavam trabalhar com temas envolvendo crimes, sangue e violência, geralmente representados com riqueza de detalhes e alguns exageros. As publicações se tornaram extremamente populares principalmente entre o público vitoriano do século XIX.

Obras que se tornaram cânones da literatura fantástica mundial como Varney The Vampire, Spring Heeled Jack, Sweeney Tood, The Demon Barber Of Fleet Street $e$ The Flying Dutchman, nasceram nessas revistas e alcançaram sucesso ainda maior após suas publicações em formas mais canônicas de narrativa, como os livros e os encadernados de época.

Se pudermos classificar uma publicação em solo nacional que venha a se equiparar com as Penny Dreadfuls, desconsiderando a estética de criação e de verso, a literatura de cordel se mostra a mais próxima. Seja pela forma barata e simples de veiculação, seja pelas narrativas que foram repassadas de forma oral por gerações até chegar às páginas da publicação, ambas as formas de texto parecem se equiparar na forma de apresentar suas narrativas por um meio menos formal, mais aberto ao povo e mais próximo de suas vidas.

Infelizmente as Penny Dreadful não chegaram sequer a pousar no Brasil. As tentativas de publicação foram arrasadas mesmo antes de serem concretizadas de forma oficial. Isso se deu centralmente pelo grande número de publicações de gêneros variados com que o editorial brasileiro vinha sendo inundado: com a possibilidade expandida de leitores, escritores de vários cantos do país se viram empenhados a publicar para esse crescente público.

Esse conjunto de fatos acabou achatando o mercado Pulp, o que resultaria em sua quase extinção prematura, e na extinção completa do que um dia poderia ter se tornado uma cultura de leitura das Penny Dreadfulls no Brasil.

O grupo Roberto Marinho também editou duas revistas que foram sucesso de longevidade, a $X-9$, que perdurou de 1941 a 1962, "A revista extraía seu material de publicações estrangeiras como Black Book Detective, The Phantom Detective e G-Men Detective" (CAUSO, 2014, p.15) e a Meia-Noite "provavelmente editada por 
Djalma Sampaio. Lançada em maio de 1948, sobreviveu até 1968. Outro sucesso de longevidade" (CAUSO, 2014, p.16).

Ambas as revistas ganharam a alcunha de "Revistas de Emoção" pela grande semelhança com as publicações em que se embasavam e pelo apelo ao público com que carregava seu editorial.

Julio França (2013) amplia essa apresentação ao articular as revistas prévias à década de 1950 como simples revisões de textos estrangeiros, o que acaba por apresentar um cenário que ainda estudava formas de adentrar esse grupo de leitores que, apesar de sedentos por material original, ainda se viam presos à mecânica de revistas estadunidenses.

A primeira e mais óbvia linha de pesquisa sugere investigar as revistas pulp brasileiras, que ganhariam força somente a partir de meados dos anos 50. As poucas que nasceram na década de 30 - como a Detective (1936-1963), a Contos Magazine (1937-1945) e a X-9 (1941-1962) consistiram basicamente de traduções e adaptações livres de material de revistas estrangeiras (Causo 2003: 233-238), muito embora esse farto material ainda se ressinta da falta de um trabalho de pesquisa que possa melhor descrevê-lo e analisá-lo. (FRANÇA, 2013, p.10)

Cardoso (2009) aponta ainda a falha dessas revistas da primeira metade do século XIX em alcançar os padrões estrangeiros em que se baseavam. Toda a sua estrutura remetia ao mercado estadunidense, o que não parecia convergir com a procura nacional das histórias. Evento esse que acabou acarretando em diversos fechamentos e poucos sucessos, ao menos até o período da ditadura militar.

No Brasil, a história dessas revistas é relatada com mais dificuldade porque não foi repentina como o surgimento da The Argosy. Aconteceu que as primeiras revistas brasileiras de fatos diversos, sofisticadas, de papel cuchê desde o início de sua publicação, como Leitura Para Todos (1905), A Ilustração Brasileira (1910) e Eu Sei Tudo (1917) apresentaram contos populares de emoção. A Ilustração, por exemplo, publicou um suplemento com Arsene Lupin. Eu Sei Tudo, novelas famosas de aventuras em série como Benita, de H. Rider Haggard e O Mundo Perdido, de H. G. Wells. Já na década seguinte, as revistas Número... (1923), Primeira (1927), Romance Semanal Intercom - Sociedade Brasileira de Estudos Interdisciplinares da Comunicação XXXII Congresso Brasileiro de Ciências da Comunicação - Curitiba, PR - 4 a 7 de setembro de 20095 (1930), Suplemento Policial (1934 - 15 de março) e A Cigarra Magazine (1934 - 1o de abril), apesar de influenciadas pelas revistas de emoção americanas, não conseguiram reunir as características fundamentais dos pulps. (CARDOSO, 2009, p. 4-5)

Contudo, foi apenas com o advento do golpe militar e da ditadura subsequente que o Brasil concebeu um grande avanço na publicação de literatura 
popular. Apoiado pela aproximação com os Estados Unidos, o ambiente editorial nacional despontou diversas publicações de ficção científica, aventura, mistério e horror, todas sob o selo do livro de bolso, tão comum no país em que se conectava o apoio.

Com o advento dessas publicações, e o investimento gradual das editoras, foi possível ver no mercado nacional uma avalanche de produções das mais variadas qualidades, livretos que se tornariam algumas décadas depois peças de colecionador, e que na época eram consumidos como jornal pelos fãs do gênero.

Apoiando-se nesse grande número de lançamentos, muitas editoras resolveram se arriscar nesse mercado que, ao menos naquele momento, parecia promissor. A "Edibolso, do poderoso Grupo Abril, que publicou um punhado de obras de Paul Anderson, Isaac Asimov, Arthur C. Clarke, Michael Crichton"(CAUSO, 2014, p.21), a "Ediouro com as séries de $F C$ alemã Perry Rhodan e Espaçonave Orion, além da coleção Fiç̧ão Science Fiction, as aventuras detetivescas de Shell Scott e Irving Leroy, e uma coleção com as novelas de Edgar Wallace"(CAUSO, 2014, p.21) além da "Cedibra nesse mesmo campo do livro de bolso, com muita FC espanhola sob pseudônimos anglos, mas com alguma coisa escrita (ou reescrita) por brasileiros no mesmo esquema"(CAUSO, 2014, p.21).

Com essa efervescência de publicações, algumas revistas conseguiram alcançar um sucesso considerável, como foi o exemplo da revista Fiç̧ão, não somente por uma estética bem construída e um bom embasamento temporal, mas também por tornar o conto brasileiro um meio de luta contra o período militar.

Nomes de peso da literatura nacional, como Ignácio de Loyola Brandão, Moacyr Scliar, Caio Fernando Abreu, João Silvério Trevisan, Sérgio Sant'Anna, Domingos Pellegrini e Rubem Fonseca, os quais viam aquele espaço como uma possibilidade de crítica e uma forma de batalhar contra os abusos da época, publicaram nessa revista, transformando o mote da revista "Histórias para o prazer da Leitura" em uma fachada para as críticas ferrenhas publicadas em seus contos.

Para Miguel Sanches Neto, Fiç̧ão "catalisou essa efervescência". "Ela é sem dúvida o mais importante centro da produção ficcional da época" (Sanches Neto, 2007: 6), caracterizando-se por buscar uma "literatura que recriasse a realidade brasileira, ou seja, que tivesse valor tanto pela qualidade literária quanto pela pertinência sociopolítica" (2007: 9). Essa ênfase se dava, na avaliação de Sanches Neto, em razão do contexto da ditadura militar (1964 a 1985): "com o recrudescimento da censura, que foi silenciando sistemática e progressivamente os intelectuais do país, impossibilitados de tratar de forma direta questões de ordem política, o conto se tornou o grande instrumento de comunicação." (SANCHES NETO, 2007 Apud CAUSO, 2014, p.22)

Apesar das temáticas permanecerem as mesmas de antes, Space Operas e aventuras interestelares ainda era material constante, os enredos dos contos desse período carregavam consigo uma crítica velada ao governo vigente. Não era incomum que publicações de cunho mais clássico, como o teatro e o romance, fossem talhados, ou até mesmo embargados pelo comitê de ética da ditadura militar. Contudo, pelo imenso acervo e continua publicação, os contos, em alguns casos, passavam sem que sua crítica fosse percebida pelo governo. 
Essa prática alavancou autores que iam contra o regime, procurando formas de lutar contra ele, mostrando ao leitor com metáforas, construções linguísticas e enredos aproximados, o quanto aquele período estava talhando a liberdade de criação não só dos artistas, mas também do povo de forma geral.

Logo após a queda da ditadura militar e a chegada da década de 1990, as revistas iniciam um processo de percepção de seu público como potenciais escritores.

Enquanto a Issac Asimov Magazine e a Galáxia 2000 permaneciam com seus editoriais no mesmo padrão de suas antecessoras, a IAM resolve arriscar promovendo um concurso que premiaria três contos com uma publicação em suas edições futuras.

Essa percepção de uma potencial produção nacional, principalmente graças ao investimento em concursos e à procura de escritores amadores, acabou ampliando o mercado, mesmo que, apesar do esforço em criar um ambiente propício para escritores amadores, a proposta de investimento não tenha perdurado.

Embora o controle da inflação estivesse vigorando, quando a IAM foi cancelada logo ali em 1994, o capital diminuído das editoras, associado a novos hábitos de leitura, (com a ascensão do segmento de autoajuda, por exemplo), fez com que os gêneros populares saíssem um pouco da mira das editoras. E com isso, as revistas de ficção. (CAUSO, 2014, p.26)

\section{O MERCADO CONTEMPORÂNEO}

O Século XXI surge então para reconstruir, ou juntar os pedaços, do que foi a era Pulp no Brasil. Com o auxílio da internet, a possibilidade de publicação se tornou um espaço mais amplo, literalmente qualquer pessoa podia escrever algo em seu desktop e publicar em um blog, um site especializado ou qualquer espaço que abrisse tal possibilidade.

As páginas pessoais foram de grande importância no começo desse século, blogs que se conectavam em grandes conglomerados, formando grupos de desconhecidos, pessoas que liam e comentavam sobre a produção do outro, um espaço livre e de pouquíssimas regras, onde seus habitantes se sentiam à vontade para escrever e comentar sobre textos autorais.

Apesar dessa grande liberdade, o acesso a esses textos permanecia como as antigas revistas de emoção, quem produzia e lia os textos eram geralmente as mesmas pessoas, as narrativas não possuíam um alcance global como um dia tivera.

Talvez um dos exemplos que escape a essa perspectiva sejam as fanzines. Revistas de caráter físico ou digital, que apesar de também não possuírem mais um grande alcance, fomentaram a criação original de muitos textos em referência a obras estrangeiras.

$\mathrm{O}$ aspecto cultural dessas revistas é, decerto, seu caráter interacional com o leitor, que vê em suas páginas uma forma de reestruturar personagens, momentos 
e histórias que fazem parte de seu universo de leitura, conhecimento de mundo e referencial intertextual.

A primeira e maior importância dos Fanzines, no que se perceber, é a cultural. Ou seja, os Fanzine, de um jeito ou de outro, em maior ou menor grau, serão incorporados à cultura brasileira onde o mesmo desenvolve mediante é a formação e amadurecimento de autores envolvidos em sua produção. Nos aspectos crítico e informativo, a liberdade criativa dos Fanzine permite a veiculação de trabalhos mais isentos e com maior profundidade onde é suma importância destacar a iniciativa de resgate de trabalhos e autores brasileiros e estrangeiros feito pelos editores de Fanzine. (ASSUMPÇÃO; PINA; JUNIOR, 2011, p.5)

Alguns investimentos para que esse cenário negativo se alterasse foram realizados. No meio físico, poucas publicações tentaram algo de suficiente relevância, casos como a revista Vimana, que produz edições especiais com narrativas fantásticas, geralmente ambientadas no Brasil, a Somnium, especializada em ficção científica, mas produzida apenas de forma digital, e algumas poucas outras que ainda investem em publicações do gênero.

O interessante dessas publicações recentes é que os escritores, em sua maioria, são amadores, autores que publicam suas obras apenas pelo prazer de serem lidos, sem recompensas monetárias ou grandes planos de publicação.

O que fica exposto é um grande número de leitores apaixonados pela escrita, uma vertente que existiu na literatura de massa desde seu início, mas que alcançou uma nova escala com a rede mundial de computadores.

Todo esse processo de leitura e releitura em que a literatura contemporânea do Pulp se apresenta é escalonado no que Jobim (2005) apontou como um novo ambiente para a percepção do texto pelo leitor, que nesse caso também é escritor e crítico, um lugar temático por todo o universo de leitura de seus habitantes e que se constrói pela mútua referência dos textos que passaram pela biblioteca virtual desses leitores.

Para falar de leituras e de leitores é sempre importante tematizar o contexto em que ambos existem, a história que está presente no próprio processamento e atribuição de sentidos, correlacionados ao texto. Mesmo a releitura dos textos do passado coloca aqueles textos em novas redes, nas quais eles se relacionam não só com outros textos, mas também com outros critérios de relevância, princípios de julgamento, atribuições de qualidade, interpretações, etc. $E$ há sempre um lugar que de algum modo afeta a subjetividade que produz textos e que os lê. $E$ afeta também a subjetividade dos que produzem a história desses textos e suas leituras. (JOBIM, 2005, p.49) 
É assim que as revistas Pulp brasileiras sobrevivem, e ouso pensar que as estrangeiras também, com contribuições de leitores, alguns escritores que insistem em manter o gênero vivo e uma imensa comunidade que vê nesses poucos criadores um porto capaz de lhes trazer literatura de qualidade, capaz de saciar suas vontades que vão se moldando com os anos a partir de suas próprias leituras e percepções de mundo.

\section{O AMBIENTE DE LEITURA}

Todas essas voltas quanto à percepção do Pulp no Brasil se mostram constantes no ambiente de insegurança em que as editoras viam tais empreitadas no decorrer das décadas. Conhecer seu público era primordial e entendê-lo começava a ser visto como uma ferramenta imprescindível para o sucesso de suas publicações.

As narrativas começavam a procurar um meio de alcançar os leitores, seus desejos que eram refletidos não mais apenas pelas revistas estrangeiras, como também por um novo escopo literário que começava a surgir graças ao avanço dessas publicações no Brasil, justificando um curto período de alavanca nas vendas dessas publicações.

O que não se tornava evidente para os escritores era que essa necessidade estava sendo preenchida de uma forma falha, as primeiras tentativas em criar uma literatura de ficção nacional, a partir dessas revistas, ditava um texto com enredos que remetiam ao solo nacional, mas a forma de apresentação permanecia exterior e estranha ao público brasileiro.

Os críticos Edgar Nolasco e Rodolfo Londero dissertam sobre a ficção científica brasileira ressaltando a capacidade deste gênero em adotar vários estilos e conteúdos, mas manter suas bases inalteráveis. No Brasil, os escritores de ficção científica aceitam essa capacidade como fato incontestável, ou seja, adotam estilos e conteúdos tipicamente brasileiros, mas mantêm as bases, as ideologias, da produção estrangeira. (NOLASCO; LONDERO, 2006, p. 49, Apud JUNIOR, 2009, p.386)

Talvez por isso um investimento tenha sido angariado para dar um nome a esse tipo de revista, reconstruir a palavra Pulp para um público que começava a ser mais amplo parecia um investimento obrigatório e imediato, dar caráter nacional ao termo e vida a uma palavra que poderia soar estranho, criando assim uma barreira para um leitor menos atento. Apesar de não ser exposto como elemento concreto, o termo Revistas de Emoção parece ter surgido no momento certo para esse empreendimento. contos de aventura, mistério e amor com as respectivas ilustrações, traduzidos das congêneres, publicadas na América onde são tratadas, até hoje, como pulps.[...]Pulp Fiction, por extensão, é a literatura de 
ficção mais fantasiosa do que as realistas de cunho psicológico, destinada ao leitor mais intelectualizado. No Brasil, a palavra emoção tornou-se emblemática porque era repetida à exaustão na publicidade do conteúdo literário dessas revistas e por isso escolheuse para adjetivá-las. (CARDOSO, 2009, p.1-2)

Contudo, mesmo com um nome instaurado e uma força recém-criada para sua consolidação, as Pulp brasileiras eram, em sua maioria, reflexo, e muitas vezes plágio, de revistas americanas, principalmente com temas policiais e aventurosos, as quais, apesar do sucesso periódico de Fast Selling, começaram a saturar seus leitores, que não conseguiam refletir naquelas narrativas elementos que se aproximassem o suficiente de suas vidas.

Para ampliar esse aspecto que já parecia muito negativo para a produção nacional, no final da década de 1950 a televisão começava a tomar o espaço que a leitura detinha como entretenimento rápido.

Esses consumidores, que viam nas revistas uma forma rápida de leitura e diversão, reconheceram na televisão um modo ainda mais rápido de prazer.

Não que estejamos culpando os grandes programas de ficção como Twilight Zone, Alfred Hitchcock Presents ou The Outer Limits, pelo contrário, sua existência permitiu que um novo público, que desconhecia o gênero, tivesse a curiosidade de buscá-lo.

Mas a passividade com que esse nível de leitores esquecia todo um universo de leitura apenas pela facilidade em recepção de outro meio midiático acabou por destruir grande parte das revistas, iniciando o que pode ser caracterizado com a grande migração dos leitores para a televisão.

O mais interessante desse aspecto é que esses programas eram roteirizados por grandes escritores de Pulp Fictions, tais como Ray Bradbury, Rod Serling, Richard Matheson e até o próprio Alfred Hitchcock, elemento esse que apenas amplia a percepção do quão fugaz e rápida era a forma com que uma considerável escala de leitores se cansava do gênero Pulp escrito e se apaixonava pelo televisivo.

Apesar desses programas terem sido pouco veiculados no Brasil, sua influência em determinados nichos de leitores, e neste caso telespectadores, foi acentuado.

Um considerável número de fãs tornou esses programas suas principais fontes de referência, suas influências não ficaram retidas unicamente a uma época, fato concedido pelos constantes remakes e reconstruções, mas sim a todo um formato de mercado ficcional que vinha se construindo com esses programas.

Sua função central parecia o simples entretenimento, mas carregava consigo, de forma intencional, as mesmas ideias com que as revistas de emoção apresentavam suas histórias, com crítica, reflexão e discussão de temas dogmáticos, elementos pouco presentes na televisão aberta daquela época.

Partindo desse cansaço em que as revistas de emoção viam seu público despencar, a força que tornava as revistas rentáveis começa a decair em escalas alarmantes, o que ocasiona um investimento potencial na produção de obras que aproximam o leitor das narrativas, as quais começariam a trabalhar com os medos locais, a Amazônia, as lendas, e outros temas que procurassem essa aproximação. 
A realidade do Brasil ainda não industrializado contrastava com a ficção policial e de aventura das revistas de emoção oriundas de outros contextos culturais. Aqui não existia o crime organizado nas cidades onde apenas se registravam assassinatos passionais ou mortes ocasionadas com lutas de facas em botequins. $O$ que havia eram batedores de carteira, vigaristas, pequenos furtos e roubos. A segurança da classe média era feita por guardas noturnos que por silvo de apitos característicos avisavam que estava tudo calmo na ronda das ruas, espantando os ladrões de galinha. Nada de assaltos a bancos, nada de cientistas loucos ou agremiações secretas. (CARDOSO, 2009, p. 12-13)

Todas essas conexões do corpo editorial com os leitores das revistas de emoção criaram o que atualmente os pesquisadores chamam de época de ouro do Pulp no Brasil, período que iria da década de 50 à década de 70, conglomerando publicações que ficariam na história da leitura brasileira por criar um verdadeiro e considerável grupo de leitores, os quais dedicavam suas leituras às revistas e romances populares do gênero.

Não à toa Geraldo Galvão Ferraz (CAUSO, 2014, p.14) aponta que Detective, revista que perdurou por algumas décadas, sendo editada e dirigida por nomes conhecidos do teatro e da literatura nacional, como Armando de Castro, Patrícia "Pagu" Galvão e Nelson Rodrigues, foi a principal referência a que o público brasileiro pode chamar de era Pulp.

Chamada de A Revista das Emoções, Detective conseguiu criar em solo nacional uma verdadeira ode ao gênero narrativo a que se propôs, tendo sido base e referência para muitas que tentariam a sorte nesse terreno durante e após seu término de publicação.

Se comparado ao mercado estadunidense, o Brasil não conseguiu equipararse ao que foi a Era Pulp americana. Os investimentos, apesar de bem recebidos pelo público, não conseguiram criar o impacto desejado por seus investidores, levando alguns críticos a pontuar que sequer existiu um mercado Pulp no Brasil, e se existiu foi ínfimo em comparação à sua referência externa, como bem apontam Causo "É difícil dizer que o Brasil teve uma pulp era compatível com a dos norteamericanos" (CAUSO, 2003, p.233) e França "Houve uma Pulp Era no Brasil? Se buscarmos na cena literária brasileira algo idêntico a Pulp Era, a resposta ao título deste tópico precisará ser, indubitavelmente, negativa" (FRANÇA, 2013, p.11).

O reflexo dessa quebra de expectativa recai na qualidade das revistas, que com a eminência do fechamento começam a reduzir ainda mais a qualidade do material e do editorial, ocasionando, fatidicamente, em um comboio de fechamentos e pedidos de falência das mesmas.

\section{OS LEITORES DO PULP NO BRASIL}

Para entendermos, ou melhor, para tomarmos nota, do que foram essas várias facetas dos leitores do Pulp no Brasil, precisamos remontar nossa perspectiva de 
leitor a um conceito mais geral do que é ler. Pela proposta de ZILBERMAN (2015) "a leitura não constitui tão somente uma ideia, com a força de um ideal. Ela contém também uma configuração mais concreta, assumindo contornos de imagem, formada por modos de representação característicos, expressões próprias e atitudes peculiares".

A ficção científica, o horror e a fantasia extrapolam essas configurações, criando as imagens e representações da fala de Zilberman a partir de um prisma disperso das noções de realidade concreta em que se pautam as descrições dos romances, por exemplo.

Para a autora, mais do que um processo de simples leitura e gravação do que é narrado, a leitura deve criar uma interação entre o texto e o leitor, um espaço onde os vazios da obra devem ser preenchidos pelas emulações do mundo externo do leitor no mundo interno da obra.

A leitura não constitui tão somente uma ideia, com a força de um ideal. Ela contém também uma configuração mais concreta, assumindo contornos de imagem, formada por modos de representação característicos, expressões próprias e atitudes peculiares. (ZILBERMAN, 2015, p.4)

Mesmo que uma imagem criada tenha sempre referência a algo existente na vida do leitor, ou em algo que ao menos se assemelhe a algo real, nas Pulps o que se mostrava era sempre uma forma de entender o mundo, as narrativas e as construções literárias, a partir de um horizonte desconhecido se comparado ao elemento real, mas conhecido pela noção de Poiesis, de construção imaginativa e de extrapolação da realidade.

Com isso, os leitores das revistas de emoção, a partir da perspectiva desse trabalho, serão pensados sob duas grandes subdivisões; O leitor que também é escritor, aquele que não necessariamente vai produzir outras narrativas, mas que vai participar da formulação do que é lido em determinado espaço de tempo e o leitor que participa da construção do texto a partir de seu horizonte particular e singular, mas que migra entre outros gêneros conforme é empurrado pelas editoras.

O primeiro tipo se refere diretamente ao leitor brasileiro das últimas cinco décadas. Esse nível de leitor, se assim podemos categorizá-lo sem generalizações, consegue se afastar tempo suficiente do espaço em que a literatura tinha destaque em décadas anteriores como leitura comunitária. Sua atitude singular e individual torna a leitura um processo além da simples recepção direta sem interconexões, seu trabalho com o texto será inteiramente reflexivo e catártico, alterando a forma de entender o texto conforme suas leituras de mundo, seu universo intertextual, atuam no processo de leitura.

Nesse primeiro nível, temos os leitores reais da proposta de Iser ${ }^{1}$. Trata-se de um leitor capaz de preencher os espaços vazios, os pontos de indeterminação levantados por Ingarden, e principalmente leitores capazes de trabalhar junto à assimetria do texto seus pontos de ancoragem no processo de recepção. 
Como proposto por Lajolo e Zilberman, são esses leitores reais que constroem o dialogismo do texto e da receptividade da obra no ambiente de leitura. A posição das autoras defende uma reflexão do texto literário em seu processo de leitura que não exclua esse processo de interação, mas que, pelo contrário, deixe convergir o texto nas realidades do leitor.

\begin{abstract}
Estes leitores de carne e osso, dos quais se ocupam os censos e que sustentam o negócio dos livros, passíveis, portanto, de serem historicizados e estudados estatisticamente, têm sua contrapartida textual: o leitor empírico, destinatário virtual de toda criação literária, é também direta ou indiretamente introjetado na obra que a ele se dirige. Assim, nomeado ou anônimo, converte-se em texto, tomando a feição de um sujeito com o qual se estabelece um diálogo, latente, mas necessário. (LAJOLO; ZILBERMAN, 2003, p.16-17)
\end{abstract}

Os leitores de Pulp Fiction, e de revistas do gênero, tornam-se atuantes na construção da narrativa, leitores que além de acompanhar escritores favoritos, obras de grande mídia e produções do estilo literário preferido, também dão respaldo a seus escritores, apontando falhas de roteiro, produzindo críticas, empenhando tempo para transformar as obras de que gostam em algo maior.

Não à toa, um dos maiores prêmios de fiç̧ão científica do mundo, muito bem representado por escritores e críticos brasileiros após o início do século XXI, premia unicamente pelo voto de seus "investidores", leitores que pagam uma determinada quantia para fazer parte desse "clube" de fãs de contos, fanzines e revistas Pulp, que concede esse prêmio todo ano em um imenso evento fechado para fãs, para leitores desse primeiro nível.

Apesar de não ser um leitor exclusivamente brasileiro, esse nível de leitura se mostrou de forma muito tardia no Brasil. Como pontuado anteriormente, apenas na ditadura militar, que trouxe consigo as mais poderosas formas de repressão, que escritores empenharam, dessa vez com afinco, a crítica à literatura e o se fazer falar a partir dela com a ficção.

Desse nível surgiram também vários leitores que se tornaram escritores, alguns já citados no corpo desse trabalho, mas alguns que valem ser citados pela contemporaneidade de seus trabalhos, como André Vianco ${ }^{2}$, Eduardo Sphor $^{3}$ e Finísia Fideli ${ }^{4}$, autores que trazem em suas bibliografias um histórico de leitura fantástica e de revistas de emoção.

O segundo nível de leitor é aquele capaz de comprar tudo o que for altamente anunciado, capaz de ler um conto dentro de uma dessas antologias gerais, mas também capaz de ler uma literatura clássica com a mesma empolgação.

Esse leitor é o mais perigoso para o escritor das revistas Pulp, pois ele pode em uma edição fazer o escritor acreditar que sua obra possui uma ótima recepção, e na outra edição simplesmente esquecer-se da mesma, deixando o autor sem nenhuma perspectiva real de recepção.

É esse leitor que Lajolo e Zilberman (2003) chamaram de desconhecido, um leitor que não consegue ser medido por empresas de análise, um personagem dentro da grande engrenagem literária que não possui um especialista para medir 
e saber o que está pensando sobre o que está lendo, mas que apenas seu histórico de leitura consegue delinear um caminho para que a obra o alcance.

Esse leitor impossível de ser medido foi o leitor prévio à década de 1960 no Brasil, um leitor que não sabia o que estava recebendo, que tomava a novidade das Fanzines, das revistas de emoção e das antologias com uma percepção nova do objeto, um ambiente a ser descoberto e explorado, mas que diferentemente do primeiro nível de leitor aqui pontuado, terminaria a leitura em si mesmo, sem que sua opinião direta, já que seu horizonte de leitura era conhecido pelas editoras, fosse revelado.

\section{APONTAMENTOS FINAIS}

Ficou exposto que as revistas Pulp não conseguiram criar um impacto imenso na cultura mercadológica de livros no Brasil, seu estado de nicho onde foi criado permanece até a contemporaneidade e não parece dar sinais de escape dessa posição.

Porém, o que fica é que, se não no mercado, no horizonte de leitura da população brasileira essas revistas tiveram um imenso escopo; a resistência em consumir literatura do gênero foi sendo quebrada paulatinamente e hoje se mostra como uma importante vertente literária mundial. Basta pensar nas consecutivas produções científicas em relação ao gênero e aos vários grupos de estudos que vêm surgindo nas últimas décadas para discutir sobre o gênero.

Se pensarmos como essa recepção tem evoluído podemos ter esperança de que esse horizonte se amplie, talvez não ao grande alcance que obteve no início do século $\mathrm{XX}$, mas ao menos que continue abrindo espaço para novos escritores que tenham interesse em se aventurar nesse espaço.

Por fim, acredita-se que este artigo conseguiu trazer um diminuto do que essas revistas trouxeram para o Brasil e como os leitores se mostraram frente à essa investida, evidenciando que os espaços para novas formas de literatura são sempre bem-vindos e atraentes a um público leitor tão miscigenado como é o brasileiro. 


\title{
Readers in Brazilian pulp era, the advent of pulp fictions
}

\begin{abstract}
This article proposes to articulate the reading relations in the Brazilian literary scene on the beginning of the XX century with the famous Pulp magazines, known as revistas de emoção. Working with a market niche during the last decades, magazines as Weird Tales, Tales From the Crypt and Mysterie Magazine formed a considerable legion of readers while being published. These magazines where an important path for so many readers to create their reading horizons and writing environments, building the literary universe of many Brazilians. Mariza Lajolo and Regina Zilberman's texts about reading, and Roberto Causos's about the Pulp in Brazil formulate the theoretical base of this work, while Iser and Genete work the discourse of the narrative and the reflex of the reader in touch with these pieces. This set of authors promote an important analysis of this impact on the Brazilian literary culture, which had led to a considerable group of readers who were not very interested in academic researches.
\end{abstract}

KEYWORDS: Pulp. Emotion magazines. Science Fiction. Fantasy. 


\section{NOTAS}

10 leitor ideal representa uma impossibilidade estrutural da comunicação. Pois um leitor ideal deveria ter o mesmo código que o autor. Mas como o autor transcodifica normalmente os códigos dominantes nos seus textos, o leitor ideal deveria ter as mesmas intenções que se manifestam nesse processo. Se supormos que isso é possível, então a comunicação se revela como supérflua, pois ela comunica algo que resulta da falta de correspondência entre os códigos de emissor e receptor. (ISER, 1996, p.65).

2 Escritor de horror mais cultuado em solo nacional, criador da lenda dos 7, uma coletânea de livros que trabalha com o mito do Vampiro a partir de uma perspectiva histórica semelhante à obra de Bram Stoker. Vianco traz a lenda vampiresca a partir da força da natureza, quebrando o paradigma usual das narrativas fantástica de horror que utilizam do mito unicamente como um monstro grotesco. Executando uma narrativa que une o medo psicológico de Stoker com lendas locais, o autor acabou conquistando os fãs brasileiros pela proximidade criada entre suas narrativas e os lugares que o leitor conhece representadosnas obras.

3 Autor recém-descoberto de fantasia, suas obras mesclam horror, mitos e fantasia em uma aventura épica durante sua famosa trilogia, obras que já ultrapassaram a marca de 700.000 obras vendidas no mundo.

4 Autora de muitas fanzines de ficção científica na década de 1990, recentemente publicou em uma antologia estadunidense o conto $A$ ressurreição de Lazaro. 


\section{REFERÊNCIAS}

ASSUMPÇÃO, D.J.F.; PINA, E.M.; JUNIOR, J.C.P.S. Fanzine como mídia alternativa: uma análise do cenário Belemense. Revista ALTERJOR, Ano 02. Vol.02. Ed.04. Jul.Dez.2011.

CARDOSO, Athos Eichler. As Revistas de Emoção no Brasil (1934-1949): O Último Lance da Invasão Cultural Americana. Trabalho apresentado no NP-Produção Editorial do IX Encontro de Núcleos de Pesquisa em Comunicação, evento componente do XXXII Congresso Brasileiro de Estudos Interdisciplinares da Comunicação. Curitiba,PR- 4 a 7 de setembro de 2009. Disponível em PDF em: $<$ http://www.intercom.org.br/papers/nacionais/2009/resumos/R4-18332.pdf>

CAUSO, Roberto de Sousa. Ficção Científica, Fantasia e Horror no Brasil: 1875 a 1950. Belo Horizonte: Editora UFMG, 2003.

Os Pulps Brasileiros e o Estatuto do Escritor de Ficção de Gênero no Brasil. Alambique: Revista acadêmica de ciência ficción y fantasia / Jornal acadêmico de ficção científica e fantasía. Vol. 2: Iss. 1, Article 5. 2014.

FRANÇA, Julio. Ecos da Pulp Era no Brasil: O Gótico e o Decadentismo em Gastão Cruls. Terra Roxa e Outras terras: Revista de Estudos Literários.Vol.26, ISSN 16782054. Dez. 2013.

GENETTE, Gerard. Palimpsestos. Trad. Luciene Guimarães e Maria Antônia Ramos Coutinho. Belo Horizonte. Faculdade de Letras. 2006.

ISER, Wolfgang. $\mathbf{O}$ ato da leitura: uma teoria do efeito estético. Trad. Johannes Kretschermer. São Paulo: Ed.34, 1996.

JOBIM, José Luiz. O Lugar da História da Literatura. Desenredo, Passo Fundo-RS, n.1, v.1, p. 40-51, Jan./Jun. 2005.

JUNIOR, Arnaldo Pinheiro Mont' Alvão. As definições de ficção científica da crítica brasileira contemporânea. Estudos Linguísticos, São Paulo, 38 (3): 381-393, SetDez. 2009.

LAJOLO, Marisa; ZILBERMAN, Regina. A construção do leitor. In: . A formação da leitura no Brasil. São Paulo: Ática, 2003, p. 13-57. científica brasileira: uma análise do gênero cyberpunk. In: NOLASCO, Edgar 
Cézar; GUERRA, Vânia Maria Lescano (Orgs.). Discurso, Alteridades e Gêneros. São Carlos: Pedro \& João Editores, 2006.

ZILBERMAN, Regina. A leitura no Brasil: sua história, suas instituições. Projeto Memória da Leitura - IEL/UNICAMP. Disponível em: www.unicamp.br/iel/memoria/projetos/ensaios/ensaio32.html. Acesso em 22 dez. 2015.

Recebido: 30 mar. 2016

Aprovado: 15 nov. 2016

DOI: $10.3895 /$ rl.v12n25.3860

Como citar: SILVA, R. F.S; PAVLOSKI, E. Os leitores brasileiros na era pulp, o advento das revistas de emoção. R. Letras,

Curitiba, v. 18, n. 23, p. 111-130, jul./dez. 2016. Disponível em: 〈https://periodicos.utfpr.edu.br/rl>. Acesso em: XXX.

Direito autoral: Este artigo está licenciado sob os termos da Licença Creative Commons-Atribuição 4.0 Internacional.

\section{(c) (1)}

